\title{
Regulation of adrenomedullin and its family peptide by RAMP system \\ - Lessons from genetically engineered mice -
}

Takayuki Shindo $^{\text {a }}$, Takayuki Sakurai ${ }^{\text {a }}$, Akiko Kamiyoshi ${ }^{\text {a }}$, Yuka Ichikawa-Shindo ${ }^{\text {a }}$ Natsumi Shimoyama ${ }^{\text {a }}$, Nobuyoshi Iinuma ${ }^{\text {a, }}$, Takuma Arai ${ }^{\text {a, }}$, Shinichi Miyagawa ${ }^{\text {b }}$

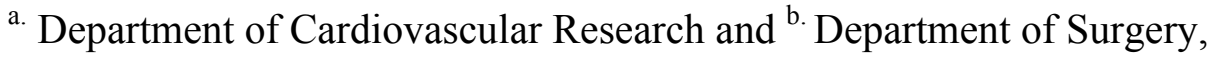
Shinshu University Graduate School of Medicine, Japan

Short title: Genetically engineered mice of adrenomedullin and RAMPs

\section{* Address for correspondence}

Takayuki Shindo, MD, PhD

Department of Cardiovascular Research

Shinshu University Graduate School of Medicine

Asahi 3-1-1, Matsumoto, Nagano, 390-8621, Japan

Tel: $+81-263-37-2578$

Fax: $+81-263-37-3437$

Email: tshindo@shinshu-u.ac.jp 


\section{ABSTRACT}

Adrenomedullin (ADM), originally identified as a vasodilating peptide, is now recognized to be a pleiotropic molecule involved in both the pathogenesis of cardiovascular diseases and circulatory homeostasis.

Homozygotes of ADM knockout mice (ADM-/-) were lethal at mid-gestation with abnormalities of vascular development and this finding clarified the angiogenic potency of ADM. Calcitonin gene-related peptide (CGRP), which has a structure and function similar to that of ADM, has been identified as a family peptide of ADM. Unlike ADM-/-, CGRP-/- were apparently normal. Therefore, the study of knockout mice first clarified the distinctly different physiological roles between ADM and CGRP.

In contrast, heterozygotes of ADM knockout mice (ADM+/-) were alive but showed blood pressure elevation, reduced neovascularization, and enhanced neointimal formation by arterial injury.

Based on these observations, there was hope ADM would have a therapeutic use. However, ADM has a short half-life in the blood stream and its application in chronic disease has limitations. Therefore, we focused on the ADM receptor system. The calcitonin-receptor-like receptor (CLR), which is the ADM receptor, associates with one of the accessory proteins, called receptor activity-modifying proteins (RAMPs). By interacting with RAMP1, CLR exhibits a high affinity for CGRP, whereas by interacting with either RAMP2 or -3, CLR exhibits a high affinity for ADM.

We generated RAMP knockout mice and found that vascular phenotypes similar to ADM-/- were reproduced only in RAMP2-/-. This shows that RAMP2 is the key 
determinant of the vascular functions of ADM. RAMP2 could be an attractive therapeutic target in cardiovascular diseases.

\section{Key words;}

adrenomedullin

receptor activity-modifying proteins

knockout mouse

angiogenesis

lymphangiogenesis

endothelial cell 


\section{INTRODUCTION}

Adrenomedullin (ADM) is a 52-amino acid vasodilating peptide first identified from human pheochromocytoma in $1993^{[1]}$. Since then, ADM has been shown to be synthesized by a variety of tissues and cell types ${ }^{[2]}$. Based on its structural homology and similar vasodilatory effects, ADM has been classified as a family peptide of calcitonin gene-related peptide (CGRP). Apart from its vasodilatory effect, ADM also exerts diuretic $^{[3]}$ and cardiotonic ${ }^{[4]}$ effects, and is involved in the regulation of hormone release $^{[5,6]}$, inflammation ${ }^{[7]}$, oxidative stress, ${ }^{[8,9]}$ and the proliferation, migration and differentiation of various cell types ${ }^{[10-12]}$. Plasma ADM is elevated in the presence of such pathological conditions as hypertension, renal failure, and heart failure ${ }^{[13,14]}$. Therefore, ADM is thought to be involved in the pathophysiology of cardiovascular diseases as well as the regulation of circulatory homeostasis.

$\mathrm{ADM}$ is a member of the calcitonin superfamily and acts via calcitonin-receptor-like receptor (CLR), a seven transmembrane $G$ protein-coupled receptor $(\mathrm{GPCR})^{[15]}$. The specificity of CLR for its ligands is regulated by a group of three receptor activity-modifying proteins, RAMP1, -2 and -3 .

To elucidate the in vivo roles of ADM, genetically engineered mice have served as a useful tool for analysis of the physiological and pathophysiological roles of ADM and its related molecules. This review summarizes the roles of ADM and RAMPs, which have been clarified through the analysis of genetically engineered mice. In addition, we introduce the novel roles of ADM-RAMP2 system in the liver, which were clarified using these mice. 


\section{ADM KOCKOUT MICE}

Three independent groups including ours have reported the outcome of targeted ADM gene disruption ${ }^{[8] ~[16] ~[17] . ~ O u r ~ s t r a t e g y ~ t o ~ k n o c k o u t ~}(\mathrm{KO})$ the ADM gene was to destroy a $2.4 \mathrm{~kb}$ fragment encompassing the $1.3-\mathrm{kb} 5$ ' -flanking region, exons $1-3$, and part of exon 4 of the ADM gene ${ }^{[16]}$.

Embryos homozygous for ADM null mutation (ADM-/-) were lethal, and no embryos could survive beyond the mid-term of gestation. The mortality rate among ADM-/- embryos at embryonic day (E) 13.5 was 83\%, and none survived to E14.5. Two of the most apparent abnormalities in ADM-/- were hemorrhage and edema. Another remarkable abnormality was poorly-developed vitelline vessels on the yolk sac (Figure $1)$.

These embryos also exhibited accumulation of pericardial effusion suggestive of cardiac failure. We speculated that ADM-/- embryos are lethal due to disruption of the vasculature and circulatory collapse.

To visualize the vascular system of the embryos, we performed angiography at E13.0, before hemorrhagic changes were detectable macroscopically (Figure 2). We injected contrast medium via the umbilical artery. After fixation, soft tissue was made transparent by xylene-treatment. In this method, the vascular system was well-visualized in wild-type (WT) embryos. Meanwhile, contrast medium showed leakage and the vascular system was not well-visualized in ADM-/- embryos. These observations suggest that the vascular system in ADM-/- embryos is leaky and thus easily causes edema and hemorrhage. 
Carron et al ${ }^{[17]}$. independently generated ADM-/- and reported ADM-/- exhibited few hemorrhage. First of all, KO mice phenotype often varies between the targeting strategies, especially for which lines of mice and embryonic stem (ES) cell lines are used. Secondly, the other group reported that ADM-/- show edema, however, our group reported that ADM-/- show edema, hemorrhage, and poorly developed arteries. In addition, we found vascular fragility associated with vascular abnormalities is the major cause of the phenotypes. We speculate that fragility of the vasculature causes vascular leakage, although the degree might vary. We think that both edema and hemorrhage are caused by the same phenomena of vascular fragility and that they are not fundamentally different phenotypes.

\section{CGRP KNOCKOUT MICE}

Calcitonin gene-related peptide (CGRP) is a 37-amino acid vasoactive peptide produced by tissue-specific alternative splicing of the primary transcript of the calcitonin/CGRP gene ${ }^{[18]}$. While calcitonin, which controls calcium homeostasis, is expressed almost exclusively in the C-cells of the thyroid gland, CGRP is widely distributed. Based on its structural homology and similar biological actions, ADM has been classified as a family peptide of CGRP. In addition to the structural and functional similarities, CGRP also uses the same receptor system as ADM. The ADM receptor, CLR, functions also as the CGRP receptor ${ }^{[15]}$. In combination with RAMP1, CLR shows higher affinity with CGRP than ADM.

Calcitonin derives from exons 1-4, whereas CGRP derives from exons 1-3 and 5-6 
from the calcitonin/CGRP gene. We also generated CGRP KO mice using a targeting DNA construct, which replaces the exon 5 encoding CGRP specific region ${ }^{[19]}$. Unlike ADM-/-, homozygotes of CGRP KO mice (CGRP-/-) were alive and apparently normal. Adult CGRP-/- showed higher blood pressure and heart rate compared with WT mice. We have shown that CGRP contributes to the regulation of cardiovascular function through inhibitory modulation of sympathetic nervous activity. With respect to the angiogenic potency of CGRP, tumor-associated angiogenesis and wound healing angiogenesis were reported to be reduced in CGRP-/- compared with those in WT mice ${ }^{[20]}{ }^{[21]}$. However, unlike ADM, CGRP does not contribute to vascular development during embryogenesis. It is noteworthy that the study of $\mathrm{KO}$ mice first clarified the distinctly different physiological roles between ADM and CGRP.

\section{BLOOD PRESSURE ALTERATION IN ADULT ADM+/- MICE}

Heterozygous KO mice of ADM (ADM+/-) were fully viable, and ADM levels in various organs of $\mathrm{ADM}+/$ - were decreased to half that of WT mice. ADM was originally identified as a strong vasodilating peptide and acute ADM administration causes blood pressure depression in animals and humans. Using ADM+/, we analyzed whether chronic alteration of the ADM level also has an influence on blood pressure.

In $\mathrm{ADM}+/$, , we evaluated the hemodynamic parameters by intraarterial cannulation $^{[16,22]}$, and found that blood pressure in $\mathrm{ADM}+/-$ mice was significantly higher than in WT (mean blood pressure: ADM+/- $128.4 \pm 2.2$ vs WT $118.7 \pm 2.4 \mathrm{~mm}$ $\mathrm{Hg})$. 
We next examined the renal perfusion pressure (RPP) of kidneys isolated from $\mathrm{ADM}+/-$ and $\mathrm{WT}^{[23]}$. Baseline RPP was significantly higher in $\mathrm{ADM}+/-$ than $\mathrm{WT}$ mice $(\mathrm{ADM}+/-93.4 \pm 4.6$, WT $85.8 \pm 4.2 \mathrm{~mm} \mathrm{Hg}) . \quad \mathrm{N}^{\mathrm{G}}$-nitro-L-arginine methyl ester (L-NAME), a nitric oxide (NO) synthase inhibitor, caused less vasoconstriction in $\mathrm{ADM}+/$ - than WT mice (\% RPP $10^{-4} \mathrm{~mol} / \mathrm{L}$ L-NAME: ADM+/- $33.1 \pm 3.3$, WT $55.5 \pm$ $7.2 \%$ ), therefore, a reduction in baseline NO production may partly explain the higher blood pressure in ADM+/-. These results support the hypothesis that ADM plays a role in the physiological regulation of vascular tone through its NO releasing activity.

Shimosawa et al. ${ }^{[8]}$ independently generated $\mathrm{ADM}+/-$ and reported no rise in blood pressure. In general, blood pressure data for $\mathrm{KO}$ mice vary depending on which method is used in the analysis. We measured arterial pressure directly using a catheter inserted into the femoral artery under anesthesia using halothane. The other group measured it using the tail cuff method in conscious animals. We think that the direct measurement is the most accurate at detecting slight differences in blood pressure between $\mathrm{KO}$ mice and WT mice.

\section{ANGIOGENESIS ALTERATION IN ADULT ADM+/- MICE}

We and other groups have shown that ADM possesses angiogenic properties in adults and not only during development ${ }^{[24-27]}$. We used a hind-limb ischemia model to evaluate the angiogenicity of $\mathrm{ADM}^{[24]}$. Following femoral artery occlusion, autoamputation of ischemic toes was frequently observed in control mice, whereas no autoamputation was observed in mice treated with ADM (50 ng/h using osmotic pumps). 
In laser Doppler perfusion imaging on day 12 after surgery, control mice showed about $70 \%$ blood flow recovery in the ischemic limb, whereas ADM-treated mice showed $98 \%$ blood flow recovery. Treatment with ADM significantly increased the number of capillaries in the ischemic limb.

We also subjected ADM+/- mice and their WT littermates to hind-limb ischemia to investigate the role of endogenous ADM on angiogenesis. On day 7 after surgery, ADM $+/-$ mice showed about $30 \%$ less blood flow recovery than WT mice. These findings indicate that both exogenous and endogenous ADM exerts novel angiogenic effects that influence the recovery of blood flow in ischemic tissue.

With respect to the mechanism of angiogenic potency, ADM has been shown to promote the proliferation and migration of endothelial cells via protein kinase A (PKA) or phosphatidylinositol 3-kinase (PI3K) dependent pathway ${ }^{[11,26,28]}$. The angiogenic effect of ADM is abrogated in endothelial nitric oxide synthase (eNOS) KO mice; therefore, the NO-releasing activity of ADM is also involved ${ }^{[25]}$. Furthermore, ADM was reported to promote the mobilization of bone marrow-derived cells in ischemia-induced collateral development ${ }^{[29]}$.

High levels of ADM expression have been detected in various types of cancer cells suggesting $\mathrm{ADM}$ is involved in tumor growth ${ }^{[30-33]}$; in fact the presence ADM is associated with more aggressive tumor phenotypes in some cancer cell lines ${ }^{[34]}$. We examined the role of $\mathrm{ADM}$ in tumor angiogenesis. By enhancing tumor angiogenesis and tumor blood flow, ADM also promoted the growth of subcutaneously transplanted sarcoma 180 tumor cells ${ }^{[24]}$. This means that caution should be exercised when 
considering the possible therapeutic applications of ADM, as one would not want to promote unfavorable angiogenesis associated with tumor growth. On the other hand, it means ADM antagonists may effectively inhibit tumor growth through the suppression of tumor angiogenesis.

\section{ADM-RAMP2 SYSTEM}

ADM-signaling is regulated by a unique control system ${ }^{[15,35-37]}$. The ADM receptor is a seven transmembrane GPCR named calcitonin-receptor like receptor (CLR). CLR associates with an accessory protein, receptor activity modifying protein (RAMP), which is comprised of about 160 amino acids and includes a single membrane-spanning domain. Three RAMP subtypes have been identified. By interacting with RAMP1, CLR exhibits a high affinity for CGRP, whereas by interacting with either RAMP2 or -3, CLR exhibits a high affinity for ADM (Figure 3). This novel system enables CLR to transduce the signals of multiple ligands, although the precise mechanism remains largely unknown.

We hypothesized that not only the receptor-ligand specificity, but also the diversity of the biological activities of ADM reflects its novel regulation by RAMPs. We analyzed the expression of $\mathrm{ADM}$ and its related genes during mid-gestational development (E11.5-E14.5), the stage at which ADM-/- embryos typically die. We found that in WT mice, ADM, CLR, RAMP2 and RAMP3 all continued to be expressed at mid-gestation. Using in situ hybridization, we detected ADM expression in the vascular system and found that, among the RAMPs, only RAMP2 was specifically 
expressed in the vasculature at that stage. We therefore speculated that it is RAMP2, which determines ADM function during vascular development and proceeded to generate RAMP2 KO mice to directly assess the functions of the ADM-RAMP2 system in vivo.

\section{RAMP2 KNOKOUT MICE SHOW EMBRYONIC LETHAL PHENOTYPE}

The targeting vector for RAMP2 KO mice was constructed to insert loxP sites encompassing exons 2 to 4 of RAMP2 and the neomycin-resistance gene ${ }^{[28]}$. After obtaining heterozygotic floxed RAMP2 mice, we crossbred them with Cre-deleter mice to delete exon 2 to 4 of the RAMP2 gene.

No RAMP2 homozygous KO (RAMP2-/-) newborns were obtained, and analysis of the embryos from timed RAMP2+/- intercrosses showed that the RAMP2-/- genotype was lethal at mid-gestation. The mortality rate among RAMP2-/- embryos was $13 \%$ at E13.5, $92 \%$ at E14.5, and $100 \%$ at E15.5. Expression of RAMP3 did not differ in RAMP2-/- and WT mice, which means there is no functional redundancy between RAMP2 and RAMP3 during development. Moreover, the expression of ADM was upregulated by more than 5-fold in RAMP2-/- mice, presumably as a compensatory response.

At E13.5, well-developed vitelline arteries were detected on the yolk sacs of WT embryos, whereas RAMP2-/- embryos had only poorly developed vitelline arteries (Figure 4, left panel).

In the embryos, the most apparent finding in RAMP2-/- mice was severe systemic 
edema (Figure 4, right panel), while some had bleeding that was observable under the skin and within organs. These phenotypes were also observed in ADM-/- embryos ${ }^{[16]}$, though RAMP2-/- showed much more severe systemic edema than ADM-/-. RAMP2-/embryos live 1 day longer than ADM-/-. A longer survival period may result in progression of the vascular leakage and therefore the edema becomes more apparent. The reason for the longer survival is still unclear, however, we speculate that other RAMPs may have some compensatory effects.

The fact that these phenotypes resemble those of ADM-/- embryos indicates that deletion of RAMP2 is almost sufficient to reproduce the major phenotypes of the vascular abnormality observed in ADM-/-.

Fritz-Six et al. ${ }^{[38]}$ independently generated RAMP2-/- mice. They also reported severe systemic edema in RAMP2-/- mice, however, they did not observe hemorrhage and concluded the cause of the lethality in RAMP2-/- embryos was abnormal lymphangiogenesis. We further discuss this point in Section 8.

\section{ANGIOGENESIS OR LYMPHANGIOGENESIS ?}

What is the cause of the edema and hemorrhage observed in ADM-/- and RAMP2-/at mid-gestation? Abnormalities in the development of blood vessels and lymphatic vessels at this stage are the most frequent suggestions, however, the main focus of ourselves and another group was somewhat different ${ }^{[28,38]}$. We mainly focused on abnormalities in the development of blood vessels ${ }^{[28]}$. Fritz-Six et al. ${ }^{[38]}$ also reported an independent line of RAMP2-/-. They reported the jugular lymph sacs of RAMP2-/- 
embryos were smaller and the lymphatic endothelial cells appeared thin and often necrotic in the RAMP2-/- ${ }^{[38]}$. The phenotypic differences between the two independent RAMP2-/- strains could be influenced by the different genetic backgrounds. Importantly, the lymphatic and blood vessel development are not mutually exclusive and even overlap. Furthermore, edema could result from the accumulation of extracellular fluid due to either excess leakage from the blood vessels or the failure of lymphatic vessels to return fluid from the interstitium. Therefore, we should identify ADM-RAMP2 signaling as a key regulator for both blood and lymphatic vessels ${ }^{[39]}$.

In our RAMP2-/- strain, the most severe edema was observed under the skin. Therefore, we sampled axillary skin flaps from embryos and evaluated both angiogenesis and lymphangiogenesis during mid-gestation in mice embryos. In the immunohistostaining, CD31, a marker of blood vessels, was fluorescent red and podoplanin, a marker of lymphatic vessel, was fluorescent green.

Figure 5 shows the time-course of angiogenesis and lymphangiogenesis during mid-gestation (E12.5-14.5) of WT embryos. During this period, the morphology of both blood vessels and lymphatic vessels changes dramatically. In blood vessels, we can detect simple plexus formation at an earlier stage and progression of hierarchy structure at a later stage. Compared with blood vessels, the development of lymphatic vessels is delayed; we can detect the appearance of larger lymphatic vessels only at a later stage. Therefore, we can evaluate the abnormalities of blood vessels from an earlier stage. On the other hand, we must evaluate lymphatic vessel development at a relatively later stage. 
ADM-/- are embryonic lethal at E13.5. At this stage, we can easily detect the poor development of blood vessels in ADM-/-. However, only narrow vessels are detected by podoplanin staining and we could not find any differences in the lymphatic vessels between WT and ADM-/- (Figure 6, left).

Compared with ADM-/-, RAMP2-/- embryos can survive 1 day longer, and we can evaluate the embryos at E14.5. At this stage, we can evaluate both blood vessel and lymphatic vessel development, and we can detect the poor development of both vessels in RAMP2-/- (Figure 6, right). In accordance with this finding, the gene expression of both angiogenic and lymphangiogenic markers was down regulated in RAMP2-/-.

Based on these data, both angiogenesis and lymphangiogenesis can be implicated in the phenotypes of the KO mice; however, blood vessel abnormalities are more likely to be the earlier event.

\section{RESCUE EXPERIMENT OF RAMP2-/- EMBRYO}

Based on the above observations, we further performed rescue experiments for RAMP2-/-. As shown in Figure 7, we aggregated RAMP2-/- and LacZ embryos to produce chimeric embryos, transferred them into the uterus of a pseudopregnant female mouse, and obtained E13.5 chimeric embryos. In this method, we observed the progression of vascular growth and suppression of edema in RAMP2-/-. In the lower chimerization case, the embryo still showed edema and poor vascular development. In the higher chimerization case, the edema was suppressed and we could detect progression of blood vessel formation with participation of many cells derived from 
LacZ embryos. These findings also support the idea that edema is mainly caused by abnormal angiogenesis in RAMP2-/-.

Recently, we established vascular endothelial cell-specific RAMP2 KO mice (E-RAMP2-/-) (unpublished). E-RAMP2-/- mice die perinatally from severe systemic edema. In contrast to conventional RAMP2-/- embryos, which die at mid-gestation, E-RAMP2-/- embryos survive until later stages of development. In E-RAMP2-/-, the lesion was limited in the endothelial cells, which likely accounts for their longer survival. Nonetheless, most E-RAMP2-/- die due to edema, reflecting endothelial abnormality and vascular leakage. These data also indicate that endogenous RAMP2 is essential for vascular endothelial cell viability and vascular integrity.

Microscopic observation of the blood vessels in RAMP2-/- embryos also revealed abnormalities; endothelial cells often showed detachment from the basement membrane and the smooth muscle layer structure was deformed in RAMP2-/- (Figure 8, left panel). We also found that blood vessels from RAMP2-/- embryos showed altered expression of molecules involved in cell adhesion and the basement membrane. In particular, the expressions of VE-cadherin, claudin 5, and type IV collagen were diminished. These molecules play important roles in the structures of the tight junction, adherence junction, and basement membrane of vascular endothelial cells, respectively. Alteration of these molecules could lead to vascular fragility and paracellular leakage from the vascular lumen, which likely explains the severe edema seen in RAMP2-/- (Figure 8, right panel). 


\section{EFFECT OF RAMP2-REDUCTION IN ADULT MICE}

Unlike their homozygous KO littermates, heterozygous $\mathrm{KO}$ mice of RAMP2 (RAMP2+/-) survived until adulthood and were fertile. In RAMP2+/- mice, the aortic expression of RAMP2 was reduced to about half that seen in WT mice. Transgenic (Tg) mice that overexpress RAMP2 in smooth muscle were reported to respond in a more sensitive manner to ADM than $\mathrm{WT}^{[40]}$. We also found that RAMP2+/- have higher blood pressure and showed a smaller blood pressure response to acutely injected ADM than $\mathrm{WT}^{[28]}$, which confirms that RAMP2 continues to be a crucial determinant of vascular dilatation of ADM in adults. On the other hand, RAMP2+/- showed no structural abnormalities in the vasculature at the basal level.

Elevated expression of ADM was reported in coronary plaques obtained from patients with unstable angina, suggesting its implications in atherosclerosis ${ }^{[41]}$. In fact, our group and other groups have reported the potential therapeutic application of ADM for atherosclerosis using genetically engineered mice. We evaluated the effect of ADM on neointimal hyperplasia and atherosclerosis using $\operatorname{ADMTg}^{[42]}$. We used a cuff-injury model, in which a polyethylene tube cuff was placed around the femoral artery for 4 weeks. The area of neointima was significantly smaller in ADMTg mice than in their wild littermates. We then crossbred ADMTg mice with ApoE KO mice (ApoE-/-) and fed the mice an atherogenic diet for 2 months. Atheromatous lesions were found to be significantly smaller in ApoE-/-/ADMTg than in ApoE-/_ ${ }^{[42]}$. On the other hand, $\mathrm{ADM}+/$-mice had increased intimal thickening of the cuff-injured femoral artery with enhanced oxidative stress and chronic adventitial inflammation ${ }^{[43]}$. 
Given these observations, it is hoped ADM will be clinically useful for the treatment of atherosclerosis; however, ADM is a peptide with a short half-life in the bloodstream, which limits its usefulness for the treatment of chronic diseases. We then evaluated whether RAMP2 can be the alternative therapeutic target of ADM. Using RAMP2+/adult mice, we generated a vascular injury model by placing a polyethylene tube cuff around the femoral artery for 4 weeks. Granulomatous tissue formation surrounding the cuff was markedly enhanced in RAMP2+/- (Figure 9, left upper panels). Neointimal formation was also greatly enhanced in RAMP2+/- (Figure 9, left lower panels). Immunohistostaining of the arteriosclerotic lesions from the cuff injury model showed intense staining of the inflammatory adhesion molecules ICAM-1 and VCAM-1 (Figure 9, right upper panels). In DHE staining, which represents the oxidative stress level of the vascular lesion, RAMP2+/- showed a markedly enhanced signal (Figure 9, right lower panels). Therefore, enhancement of oxidative stress and inflammation is the cause of severe arteriosclerosis in RAMP2+/- mice.

These findings suggest that RAMP2 is the key determinant of the vascular functions of ADM and that RAMP2 could be an alternative therapeutic target of ADM.

\section{ADM-RAMP2 SYSTEM IN LIVER SINUSOIDAL ENDOTHRLIAL CELLS}

Genetically altered mice are a powerful tool with which to visualize the significance of the endogenous ADM-RAMP2 system. We will now introduce the novel roles of ADM-RAMP2 system in the liver, which were clarified using KO mice.

Donor organ damage caused by cold preservation is a major problem affecting liver 
transplantation. Cold preservation most easily damages liver sinusoidal endothelial

cells (LSECs) ${ }^{[44,45]}$, which suggests that protection of LSECs from the injury could preserve liver function and increase the likelihood of a successful outcome after transplantation. Information about the molecules modulating LSEC function can provide the basis for new therapeutic strategies.

$\mathrm{ADM}$ is abundant in vascular endothelial cells, but ADM expression level is comparatively low in liver, and little is known about its function there. On the other hand, we found both ADM and its receptors are expressed in LSECs. To test the applicability of ADM, we assessed its effect on damage caused by cold-treatment ${ }^{[46]}$. We found that perfusion with ADM protected livers from cold-induced damage in an in vivo model. Conversely, the liver injury was exacerbated in ADM+/- and RAMP2+/mice. Based on these findings, we suggest that the ADM-RAMP2 system in LSECs is a potential therapeutic target for improving the preservation of donor organs for liver transplantation.

\section{INDUCTION OF LIVER SINUSOIDAL ENDOTHELIAL CELLS BY MODULATION OF ADM-RAMP2 SYSTEM}

We found both ADM-/- and RAMP2 -/- embryos show poor vascular development and hemorrhage within the liver. From these observations, we speculated that the ADM-RAMP2 system plays a critical role in vascular development of the liver.

ES cells are a useful source for various cell lineages. So far, however, progress toward reconstitution of mature liver morphology and function has been limited. We 
hypothesized that differentiation of liver specific endothelial cells and reconstitution of the vasculature are key elements necessary for the regeneration of mature liver. We evaluated the role of ADM-RAMP2 signaling in LSEC development and the induction of LSEC differentiation for the reconstitution of liver morphogenesis using murine ES cell-derived embryoid bodies $(\mathrm{EB})^{[47]}$.

LSECs have unique structural and functional characteristics; LSECs possess fenestrae and robust endocytotic activity. Several similarities between lymphatic endothelial cells and LSECs have been noted. For example, both cells have minimal basement membranes and loose cell-cell junctions, and express lymphatic vessel endothelial hyaluronan receptor-1 (LYVE-1). In the EB differentiation system, we found that co-administration of ADM and SB431542, an inhibitor of TGF $\beta$ receptor type 1, markedly enhanced differentiation of LYVE-1-positive endothelial cells. These cells also possessed fenestrae-like structures, a key morphological feature of LSECs. Furthermore, when we continued treatment up to day 24, we found LYVE-1-positive endothelial cells migrated to and made contact with albumin-positive hepatocyte-like cells in EBs. In RAMP2-null liver, by contrast, LYVE-1 was downregulated in LSECs, and the sinusoidal structure was disrupted.

Our findings show the importance of ADM-RAMP2 signaling for the development of LSECs. The ADM-RAMP2 system plays a critical role in the differentiation of LSECs and in sinusoidal morphogenesis. The system could be the potential target for the induction of LSECs for regenerative medicine. 


\section{PHENOTYPES OF RAMP1 AND RAMP3 KNOCKOUT MICE}

RAMP3 has been shown to work with CLR to function as another ADM receptor ${ }^{[48]}$. However, our finding that RAMP3 is expressed at WT levels in RAMP2-/- mice confirms that RAMP3 cannot compensate for the absence of RAMP2 during vascular development. We also found endothelial cell lines overexpressing RAMP3 did not show either enhanced angiogenesis or improved vascular stability ${ }^{[28]}$. In fact, RAMP3-/- mice live apparently normally with no abnormalities in vascular development ${ }^{[49]}$. Recently, Barrick et al. ${ }^{[50]}$ reported on the mouse line renin(Ren)TgMK x RAMP3-/-. RenTgMK mice have high and constant secretion of renin from the liver, elevated circulating levels of angiotensin II, and chronic hypertension. In this line, only male mice showed cardiac hypertrophy and heart failure. ADM and RAMP3 expression is potently regulated by estrogen; the estrogen binds directly to the ADM promoter region and RAMP3 intron ${ }^{[51]}$. Therefore, it may be possible that RAMP3 has sex-dependent roles. Regulation of RAMP2 and RAMP3 in some pathological situations is also different, particularly in an endotoxemia model, where RAMP2 and CLR are downregulated, but RAMP3 is markedly upregulated ${ }^{[52]}$. It was also suggested that RAMP3 may be involved in post-endocytic receptor trafficking, as it presents a PDZ type I domain ${ }^{[53]}$.

Contrary to RAMP2 and 3, RAMP1 is thought to bind with CLR and work mainly as CGRP receptor. RAMP1-/- mice are reported to be born normally and present no obvious abnormalities in their appearances ${ }^{[54]}$. RAMP1-/- exhibited higher blood pressure and LPS-induced inflammatory responses of the RAMP1-/- revealed transient 
higher serum levels of inflammatory cytokines, including MCP-1, IL-12, TNF- $\alpha$, IFN- $\gamma$, and IL-6. These results resemble the phenotypes of CGRP-/- mice. As we reported, CGRP-/- mice showed blood pressure elevation ${ }^{[19]}$. CGRP-/- mice also showed altered expression of inflammatory cytokines in both acute and chronic liver injury models ${ }^{[55,}$ 56]. On the other hand, RAMP1 Tg mice, which overexpress human RAMP1 ubiquitously, were reported to show markedly attenuated responses to angiotensin II-induced hypertension ${ }^{[57]}$. The pressor response to the CGRP receptor antagonist, CGRP8-37, was greater in RAMP1 Tg mice than in WT mice, confirming a greater antihypertensive action of endogenous CGRP in RAMP1 Tg mice. These results indicate that CGRP signaling through CLR/RAMP1 regulates both vascular relaxation and inflammatory cytokine production.

\section{SUMMARY}

Observations of genetically engineered mice help us to understand the novel functions of $\mathrm{ADM}$ and its related molecules in vivo. While $\mathrm{ADM}$ can not be categorized as a simple vasodilating peptide, it does have protective effects on organs and the vasculature at postnatal stages and plays an important role in morphogenesis during development. Because of its wide range of bioactivity, ADM has been attracting a lot of attention for its potential clinical applications.

On the other hand, the clinical applicability of ADM, like that of other bioactive endogenous peptides, has two limitations: ADM has a very short half-life in the blood and the cost of the recombinant protein is very high, together which make the use of 
ADM impractical for the treatment of chronic diseases. It is noteworthy that we were able to modulate the vascular function of ADM by modulating RAMPs. RAMP2 in particular could be a therapeutic target via which to manipulate the vascular functions of ADM. Because RAMPs are low molecular weight proteins, structural analysis and the synthesis of specific agonists or antagonists are much more realistic compared with the ADM receptor CLR, which belongs to seven transmembrane GPCRs.

Figure 10 summarizes the role of the vascular ADM-RAMP2 system. The vascular ADM-RAMP2 system plays critical roles in the regulation of vascular integrity, including the maintenance of vascular structure, regulation of angiogenesis, and vasoprotection against vascular injury. In that context, studies of ADM and RAMP2 should bring about novel approaches for the treatment of diseases derived from vascular failure.

However, caution should be exercised concerning the possibility that RAMPs associate with other GPCRs and possess broader roles than ADM and CGRP. In particular, RAMP heterodimerization with calcitonin receptors is required for the formation of amylin receptors ${ }^{[58]}{ }^{[59]}$. More recent work has revealed that the RAMPs may modulate other functions such as receptor internalization and recycling and also the strength of activation of downstream signaling pathways ${ }^{[60]}$. Further studies, including conditional gene targeting models, which enable the spatial and temporal modulation of RAMP gene expression, are needed to elucidate the more detailed pathophysiological roles of the RAMP system. 


\section{Acknowledgement}

This study was supported by Funding Program for Next Generation World-Leading Researchers (NEXT Program) from Cabinet Office, Government of Japan.

\section{Abbreviations}

$\mathrm{ADM}=$ adrenomedullin

CGRP $=$ calcitonin gene-related peptide

CLR $=$ calcitonin-receptor-like receptor

$\mathrm{RAMP}=$ receptor activity-modifying protein

GPCR $=\mathrm{G}$ protein-coupled receptor

$\mathrm{KO}=$ knockout

$\mathrm{WT}=$ wild-type

$\mathrm{Tg}=$ transgenic

LSEC $=$ liver sinusoidal endothelial cell 


\section{Figure legends}

\section{Figure 1.}

Appearance of embryonic day (E)13.5 yolk sac (upper panels) and embryos (lower panels) of ADM-/- and WT. Well-developed vitelline vessels are detected on yolk sacs of wild-type embryos but are poorly developed in ADM-/- embryos. ADM-/- showed systemic edema and hemorrhage.

\section{Figure 2.}

Angiography of E13.0 embryos. Contrast medium shows leakage and the vascular system is not well-visualized in ADM-/- embryos.

\section{Figure 3.}

Schema of the ADM receptor system. Calcitonin-receptor like receptor (CLR) associates with one of the accessory proteins, receptor activity modifying proteins (RAMPs). By interacting with RAMP1, CLR acquires a high affinity for CGRP, whereas by interacting with either RAMP2 or -3, CLR acquires a high affinity for ADM.

\section{Figure 4.}

Appearance of E13.5 yolk sac (left panels) and RAMP2-/- and wild-type embryos (right panels). RAMP2-/- embryos show similar phenotypes with ADM-/- (poorly developed 
vitelline vessels and edema).

\section{Figure 5.}

Schema of whole-mount immunohistostaining of blood vessels and lymphatic vessels in the skin flap of WT embryos. Compared with blood vessels, the development of lymphatic vessels is delayed and larger lymphatic vessels are detected only at a later stage.

\section{Figure 6.}

Result for whole-mount immunohistostaining of blood vessels and lymphatic vessels in wild-type, ADM-/- and RAMP2-/-.

Left panel; ADM-/- are embryonic lethal at E13.5. At this stage, we can easily detect the poor development of blood vessels in ADM-/- compared with wild-type. However, no difference in lymphatic vessels is discernible.

Right panel; RAMP2-/- are embryonic lethal at E14.5. At this stage, we can detect the poor development of both blood and lymphatic vessels in RAMP2-/-

\section{Figure 7.}

Rescue of angiogenesis and suppression of edema by chimerization of RAMP2-/- with LacZ mice embryos. Methods (left panel) and appearances of embryos and liver sections (right panel) are shown. In the lower chimerization case, the embryo showed systemic edema and poor vascular development. In the higher chimerization case, the edema was suppressed and blood vessel formation was facilitated. 


\section{Figure 8.}

Abnormalities of vascular structure and gene expression in E13.5 RAMP2 -/- embryos.

Left panel; Immunohistochemical staining of aorta; green, type IV collagen; red, phalloidin (used for labeling of actin); blue, DAPI. The layer structure of the vascular wall showed severe deformity in RAMP2-/-.

Right panel; Quantitative real-time PCR analysis of gene expression in the artery from E13.5 embryos. RAMP2-/- showed downregulation of tight junction, adherence junction, and basement membrane molecules.

\section{Figure 9.}

Evaluation of arteriosclerosis after vascular injury by placing a polyethylene tube cuff around a femoral artery for 4 weeks.

Left upper panels; Masson-Trichrome (MT) staining of the cuffed artery and its surrounding tissue. Granulomatous tissue formation surrounding the cuff was markedly enhanced in RAMP2+/-. Left lower panels; Elastica van Gieson (EVG) staining showing neointimal formation. Neointima thickness was greatly enhanced in RAMP2+/-.

Right upper panels; Immunohistostaining of ICAM-1 and VCAM-1. Right lower panels; dihydroethidium (DHE)-staining. The neointima formed in RAMP2+/- mice showed greatly enhanced staining. 
Figure 10.

Roles of ADM-RAMP2 system in vasculature and its future perspectives. 


\section{REFERENCES}

[1] Kitamura, K.; Kangawa, K.; Kawamoto, M.; Ichiki, Y.; Nakamura, S.; Matsuo, H.; Eto, T. Adrenomedullin: a novel hypotensive peptide isolated from human pheochromocytoma. Biochem Biophys Res Commun, 1993, 192, 553-560.

[2] Ichiki, Y.; Kitamura, K.; Kangawa, K.; Kawamoto, M.; Matsuo, H.; Eto, T. Distribution and characterization of immunoreactive adrenomedullin in human tissue and plasma. FEBS Lett, 1994, 338, 6-10.

[3] Jougasaki, M.; Wei, C.M.; Aarhus, L.L.; Heublein, D.M.; Sandberg, S.M.; Burnett, J.C., Jr. Renal localization and actions of adrenomedullin: a natriuretic peptide. Am J Physiol, 1995, 268, F657-663.

[4] Nishikimi, T.; Matsuoka, H. Cardiac adrenomedullin: its role in cardiac hypertrophy and heart failure. Curr Med Chem Cardiovasc Hematol Agents, 2005, 3, 231-242.

[5] Samson, W.K.; Murphy, T.; Schell, D.A. A novel vasoactive peptide, adrenomedullin, inhibits pituitary adrenocorticotropin release. Endocrinology, 1995, 136, 2349-2352.

[6] Petrie, M.C.; Hillier, C.; Morton, J.J.; McMurray, J.J. Adrenomedullin selectively inhibits angiotensin II-induced aldosterone secretion in humans. $J$ Hypertens, 2000, 18, 61-64.

[7] Isumi, Y.; Kubo, A.; Katafuchi, T.; Kangawa, K.; Minamino, N. Adrenomedullin suppresses interleukin-1beta-induced tumor necrosis factor-alpha production in Swiss 3T3 cells. FEBS Lett, 1999, 463, 110-114.

[8] Shimosawa, T.; Shibagaki, Y.; Ishibashi, K.; Kitamura, K.; Kangawa, K.; Kato, S.; Ando, K.; Fujita, T. Adrenomedullin, an endogenous peptide, counteracts cardiovascular damage. Circulation, 2002, 105, 106-111.

[9] Shimosawa, T.; Ogihara, T.; Matsui, H.; Asano, T.; Ando, K.; Fujita, T. Deficiency of adrenomedullin induces insulin resistance by increasing oxidative stress. Hypertension, 2003, 41, 1080-1085.

[10] Kano, H.; Kohno, M.; Yasunari, K.; Yokokawa, K.; Horio, T.; Ikeda, M.; Minami, M.; Hanehira, T.; Takeda, T.; Yoshikawa, J. Adrenomedullin as a novel antiproliferative factor of vascular smooth muscle cells. J Hypertens, 1996, 14, 209-213. 
[11] Miyashita, K.; Itoh, H.; Sawada, N.; Fukunaga, Y.; Sone, M.; Yamahara, K.; Yurugi, T.; Nakao, K. Adrenomedullin promotes proliferation and migration of cultured endothelial cells. Hypertens Res, 2003, 26 Suppl, S93-98.

[12] Iwasaki, H.; Eguchi, S.; Shichiri, M.; Marumo, F.; Hirata, Y. Adrenomedullin as a novel growth-promoting factor for cultured vascular smooth muscle cells: role of tyrosine kinase-mediated mitogen-activated protein kinase activation. Endocrinology, 1998, 139, 3432-3441.

[13] Kobayashi, K.; Kitamura, K.; Etoh, T.; Nagatomo, Y.; Takenaga, M.; Ishikawa, T.; Imamura, T.; Koiwaya, Y.; Eto, T. Increased plasma adrenomedullin levels in chronic congestive heart failure. Am Heart J, 1996, 131, 994-998.

[14] Ishimitsu, T.; Nishikimi, T.; Saito, Y.; Kitamura, K.; Eto, T.; Kangawa, K.; Matsuo, H.; Omae, T.; Matsuoka, H. Plasma levels of adrenomedullin, a newly identified hypotensive peptide, in patients with hypertension and renal failure. $J$ Clin Invest, 1994, 94, 2158-2161.

[15] McLatchie, L.M.; Fraser, N.J.; Main, M.J.; Wise, A.; Brown, J.; Thompson, N.; Solari, R.; Lee, M.G.; Foord, S.M. RAMPs regulate the transport and ligand specificity of the calcitonin-receptor-like receptor. Nature, 1998, 393, 333-339.

[16] Shindo, T.; Kurihara, Y.; Nishimatsu, H.; Moriyama, N.; Kakoki, M.; Wang, Y.; Imai, Y.; Ebihara, A.; Kuwaki, T.; Ju, K.H.; Minamino, N.; Kangawa, K.; Ishikawa, T.; Fukuda, M.; Akimoto, Y.; Kawakami, H.; Imai, T.; Morita, H.; Yazaki, Y.; Nagai, R.; Hirata, Y.; Kurihara, H. Vascular abnormalities and elevated blood pressure in mice lacking adrenomedullin gene. Circulation, 2001, 104, 1964-1971.

[17] Caron, K.M.; Smithies, O. Extreme hydrops fetalis and cardiovascular abnormalities in mice lacking a functional Adrenomedullin gene. Proc Natl Acad Sci US A, 2001, 98, 615-619.

[18] Rosenfeld, M.G.; Mermod, J.J.; Amara, S.G.; Swanson, L.W.; Sawchenko, P.E.; Rivier, J.; Vale, W.W.; Evans, R.M. Production of a novel neuropeptide encoded by the calcitonin gene via tissue-specific RNA processing. Nature, 1983, 304, 129-135.

[19] Oh-hashi, Y.; Shindo, T.; Kurihara, Y.; Imai, T.; Wang, Y.; Morita, H.; Imai, Y.; Kayaba, Y.; Nishimatsu, H.; Suematsu, Y.; Hirata, Y.; Yazaki, Y.; Nagai, R.; Kuwaki, T.; Kurihara, H. Elevated sympathetic nervous activity in mice 
deficient in alphaCGRP. Circ Res, 2001, 89, 983-990.

[20] Toda, M.; Suzuki, T.; Hosono, K.; Hayashi, I.; Hashiba, S.; Onuma, Y.; Amano, H.; Kurihara, Y.; Kurihara, H.; Okamoto, H.; Hoka, S.; Majima, M. Neuronal system-dependent facilitation of tumor angiogenesis and tumor growth by calcitonin gene-related peptide. Proceedings of the National Academy of Sciences of the United States of America, 2008, 105, 13550-13555.

[21] Toda, M.; Suzuki, T.; Hosono, K.; Kurihara, Y.; Kurihara, H.; Hayashi, I.; Kitasato, H.; Hoka, S.; Majima, M. Roles of calcitonin gene-related peptide in facilitation of wound healing and angiogenesis. Biomedicine \& pharmacotherapy = Biomedecine \& pharmacotherapie, 2008, 62, 352-359.

[22] Shindo, T.; Kurihara, H.; Maemura, K.; Kurihara, Y.; Kuwaki, T.; Izumida, T.; Minamino, N.; Ju, K.H.; Morita, H.; Oh-hashi, Y.; Kumada, M.; Kangawa, K.; Nagai, R.; Yazaki, Y. Hypotension and resistance to lipopolysaccharide-induced shock in transgenic mice overexpressing adrenomedullin in their vasculature. Circulation, 2000, 101, 2309-2316.

[23] Nishimatsu, H.; Hirata, Y.; Shindo, T.; Kurihara, H.; Kakoki, M.; Nagata, D.; Hayakawa, H.; Satonaka, H.; Sata, M.; Tojo, A.; Suzuki, E.; Kangawa, K.; Matsuo, H.; Kitamura, T.; Nagai, R. Role of endogenous adrenomedullin in the regulation of vascular tone and ischemic renal injury: studies on transgenic/knockout mice of adrenomedullin gene. Circ Res, 2002, 90, 657-663.

[24] Iimuro, S.; Shindo, T.; Moriyama, N.; Amaki, T.; Niu, P.; Takeda, N.; Iwata, H.; Zhang, Y.; Ebihara, A.; Nagai, R. Angiogenic effects of adrenomedullin in ischemia and tumor growth. Circ Res, 2004, 95, 415-423.

[25] Abe, M.; Sata, M.; Nishimatsu, H.; Nagata, D.; Suzuki, E.; Terauchi, Y.; Kadowaki, T.; Minamino, N.; Kangawa, K.; Matsuo, H.; Hirata, Y.; Nagai, R. Adrenomedullin augments collateral development in response to acute ischemia. Biochemical and biophysical research communications, 2003, 306, 10-15.

[26] Miyashita, K.; Itoh, H.; Sawada, N.; Fukunaga, Y.; Sone, M.; Yamahara, K.; Yurugi-Kobayashi, T.; Park, K.; Nakao, K. Adrenomedullin provokes endothelial Akt activation and promotes vascular regeneration both in vitro and in vivo. FEBS Lett, 2003, 544, 86-92.

[27] Iwase, T.; Nagaya, N.; Fujii, T.; Itoh, T.; Ishibashi-Ueda, H.; Yamagishi, M.; Miyatake, K.; Matsumoto, T.; Kitamura, S.; Kangawa, K. Adrenomedullin 
enhances angiogenic potency of bone marrow transplantation in a rat model of hindlimb ischemia. Circulation, 2005, 111, 356-362.

[28] Ichikawa-Shindo, Y.; Sakurai, T.; Kamiyoshi, A.; Kawate, H.; Iinuma, N.; Yoshizawa, T.; Koyama, T.; Fukuchi, J.; Iimuro, S.; Moriyama, N.; Kawakami, H.; Murata, T.; Kangawa, K.; Nagai, R.; Shindo, T. The GPCR modulator protein RAMP2 is essential for angiogenesis and vascular integrity. $J$ Clin Invest, 2008, 118, 29-39.

[29] Abe, M.; Sata, M.; Suzuki, E.; Takeda, R.; Takahashi, M.; Nishimatsu, H.; Nagata, D.; Kangawa, K.; Matsuo, H.; Nagai, R.; Hirata, Y. Effects of adrenomedullin on acute ischaemia-induced collateral development and mobilization of bone-marrow-derived cells. Clinical science, 2006, 111, 381-387.

[30] Martinez, A.; Vos, M.; Guedez, L.; Kaur, G.; Chen, Z.; Garayoa, M.; Pio, R.; Moody, T.; Stetler-Stevenson, W.G.; Kleinman, H.K.; Cuttitta, F. The effects of adrenomedullin overexpression in breast tumor cells. J Natl Cancer Inst, 2002, 94, 1226-1237.

[31] Li, Z.; Takeuchi, S.; Otani, T.; Maruo, T. Implications of adrenomedullin expression in the invasion of squamous cell carcinoma of the uterine cervix. Int J Clin Oncol, 2001, 6, 263-270.

[32] Forneris, M.; Gottardo, L.; Albertin, G.; Malendowicz, L.K.; Nussdorfer, G.G. Expression and function of adrenomedullin and its receptors in Conn's adenoma cells. Int J Mol Med, 2001, 8, 675-679.

[33] Rocchi, P.; Boudouresque, F.; Zamora, A.J.; Muracciole, X.; Lechevallier, E.; Martin, P.M.; Ouafik, L. Expression of adrenomedullin and peptide amidation activity in human prostate cancer and in human prostate cancer cell lines. Cancer Res, 2001, 61, 1196-1206.

[34] Hata, K.; Takebayashi, Y.; Akiba, S.; Fujiwaki, R.; Iida, K.; Nakayama, K.; Nakayama, S.; Fukumoto, M.; Miyazaki, K. Expression of the adrenomedullin gene in epithelial ovarian cancer. Mol Hum Reprod, 2000, 6, 867-872.

[35] Kuwasako, K.; Cao, Y.N.; Nagoshi, Y.; Kitamura, K.; Eto, T. Adrenomedullin receptors: pharmacological features and possible pathophysiological roles. Peptides, 2004, 25, 2003-2012.

[36] Parameswaran, N.; Spielman, W.S. RAMPs: The past, present and future. 
Trends Biochem Sci, 2006, 31, 631-638.

[37] Morfis, M.; Christopoulos, A.; Sexton, P.M. RAMPs: 5 years on, where to now? Trends Pharmacol Sci, 2003, 24, 596-601.

[38] Fritz-Six, K.L.; Dunworth, W.P.; Li, M.; Caron, K.M. Adrenomedullin signaling is necessary for murine lymphatic vascular development. J Clin Invest, 2008, $118,40-50$.

[39] Kahn, M.L. Blood is thicker than lymph. The Journal of clinical investigation, $2008,118,23-26$.

[40] Tam, C.W.; Husmann, K.; Clark, N.C.; Clark, J.E.; Lazar, Z.; Ittner, L.M.; Gotz, J.; Douglas, G.; Grant, A.D.; Sugden, D.; Poston, L.; Poston, R.; McFadzean, I.; Marber, M.S.; Fischer, J.A.; Born, W.; Brain, S.D. Enhanced vascular responses to adrenomedullin in mice overexpressing receptor-activity-modifying protein 2 . Circulation research, 2006, 98, 262-270.

[41] Hojo, Y.; Ikeda, U.; Ohya, K.; Ichida, M.; Kario, K.; Takahashi, M.; Ikeda, M.; Minota, S.; Isumi, Y.; Minamino, N.; Ishimitsu, T.; Shimada, K. Interaction between monocytes and vascular endothelial cells induces adrenomedullin production. Atherosclerosis, 2001, 155, 381-387.

[42] Imai, Y.; Shindo, T.; Maemura, K.; Sata, M.; Saito, Y.; Kurihara, Y.; Akishita, M.; Osuga, J.; Ishibashi, S.; Tobe, K.; Morita, H.; Oh-hashi, Y.; Suzuki, T.; Maekawa, H.; Kangawa, K.; Minamino, N.; Yazaki, Y.; Nagai, R.; Kurihara, H. Resistance to neointimal hyperplasia and fatty streak formation in mice with adrenomedullin overexpression. Arterioscler Thromb Vasc Biol, 2002, 22, 1310-1315.

[43] Kawai, J.; Ando, K.; Tojo, A.; Shimosawa, T.; Takahashi, K.; Onozato, M.L.; Yamasaki, M.; Ogita, T.; Nakaoka, T.; Fujita, T. Endogenous adrenomedullin protects against vascular response to injury in mice. Circulation, 2004, 109, 1147-1153.

[44] McKeown, C.M.; Edwards, V.; Phillips, M.J.; Harvey, P.R.; Petrunka, C.N.; Strasberg, S.M. Sinusoidal lining cell damage: the critical injury in cold preservation of liver allografts in the rat. Transplantation, 1988, 46, 178-191.

[45] Caldwell-Kenkel, J.C.; Currin, R.T.; Tanaka, Y.; Thurman, R.G.; Lemasters, J.J. Reperfusion injury to endothelial cells following cold ischemic storage of rat livers. Hepatology, 1989, 10, 292-299. 
[46] Iinuma, N.; Sakurai, T.; Kamiyoshi, A.; Ichikawa-Shindo, Y.; Arai, T.; Yoshizawa, T.; Koyama, T.; Uetake, R.; Kawate, H.; Muto, S.; Tagawa, Y.; Miyagawa, S.; Shindo, T. Adrenomedullin in sinusoidal endothelial cells play protective roles against cold injury of liver. Peptides, 2010, 31, 865-871.

[47] Arai, T.; Sakurai, T.; Kamiyoshi, A.; Ichikawa-Shindo, Y.; Iinuma, N.; Iesato, Y.; Koyama, T.; Yoshizawa, T.; Uetake, R.; Yamauchi, A.; Yang, L.; Kawate, H.; Ogawa, S.; Kobayashi, A.; Miyagawa, S.; Shindo, T. Induction of LYVE-1/stabilin-2-positive liver sinusoidal endothelial-like cells from embryoid bodies by modulation of adrenomedullin-RAMP2 signaling. Peptides, 2011, 32, 1855-1865.

[48] Sexton, P.M.; Albiston, A.; Morfis, M.; Tilakaratne, N. Receptor activity modifying proteins. Cell Signal, 2001, 13, 73-83.

[49] Dackor, R.; Fritz-Six, K.; Smithies, O.; Caron, K. Receptor activity-modifying proteins 2 and 3 have distinct physiological functions from embryogenesis to old age. J Biol Chem, 2007, 282, 18094-18099.

[50] Barrick, C.J.; Lenhart, P.M.; Dackor, R.T.; Nagle, E.; Caron, K.M. Loss of receptor activity-modifying protein 3 exacerbates cardiac hypertrophy and transition to heart failure in a sex-dependent manner. Journal of molecular and cellular cardiology, 2012, 52, 165-174.

[51] Watanabe, H.; Takahashi, E.; Kobayashi, M.; Goto, M.; Krust, A.; Chambon, P.; Iguchi, T. The estrogen-responsive adrenomedullin and receptor-modifying protein 3 gene identified by DNA microarray analysis are directly regulated by estrogen receptor. Journal of molecular endocrinology, 2006, 36, 81-89.

[52] Ono, Y.; Okano, I.; Kojima, M.; Okada, K.; Kangawa, K. Decreased gene expression of adrenomedullin receptor in mouse lungs during sepsis. Biochem Biophys Res Commun, 2000, 271, 197-202.

[53] Bomberger, J.M.; Parameswaran, N.; Hall, C.S.; Aiyar, N.; Spielman, W.S. Novel function for receptor activity-modifying proteins (RAMPs) in post-endocytic receptor trafficking. J Biol Chem, 2005, 280, 9297-9307.

[54] Tsujikawa, K.; Yayama, K.; Hayashi, T.; Matsushita, H.; Yamaguchi, T.; Shigeno, T.; Ogitani, Y.; Hirayama, M.; Kato, T.; Fukada, S.; Takatori, S.; Kawasaki, H.; Okamoto, H.; Ikawa, M.; Okabe, M.; Yamamoto, H. Hypertension and dysregulated proinflammatory cytokine production in receptor 
activity-modifying protein 1-deficient mice. Proceedings of the National Academy of Sciences of the United States of America, 2007, 104, 16702-16707.

[55] Kamiyoshi, A.; Sakurai, T.; Ichikawa-Shindo, Y.; Fukuchi, J.; Kawate, H.; Muto, S.; Tagawa, Y.; Shindo, T. Endogenous alphaCGRP protects against concanavalin A-induced hepatitis in mice. Biochemical and biophysical research communications, 2006, 343, 152-158.

[56] Kamiyoshi, A.; Sakurai, T.; Ichikawa-Shindo, Y.; Iinuma, N.; Kawate, H.; Yoshizawa, T.; Koyama, T.; Muto, S.; Shindo, T. Endogenous alpha-calcitonin gene-related peptide mitigates liver fibrosis in chronic hepatitis induced by repeated administration of concanavalin A. Liver international : official journal of the International Association for the Study of the Liver, 2009, 29, 642-649.

[57] Sabharwal, R.; Zhang, Z.; Lu, Y.; Abboud, F.M.; Russo, A.F.; Chapleau, M.W. Receptor activity-modifying protein 1 increases baroreflex sensitivity and attenuates Angiotensin-induced hypertension. Hypertension, 2010, 55, 627-635.

[58] Muff, R.; Buhlmann, N.; Fischer, J.A.; Born, W. An amylin receptor is revealed following co-transfection of a calcitonin receptor with receptor activity modifying proteins-1 or -3. Endocrinology, 1999, 140, 2924-2927.

[59] Christopoulos, G.; Perry, K.J.; Morfis, M.; Tilakaratne, N.; Gao, Y.; Fraser, N.J.; Main, M.J.; Foord, S.M.; Sexton, P.M. Multiple amylin receptors arise from receptor activity-modifying protein interaction with the calcitonin receptor gene product. Molecular pharmacology, 1999, 56, 235-242.

[60] Sexton, P.M.; Morfis, M.; Tilakaratne, N.; Hay, D.L.; Udawela, M.; Christopoulos, G.; Christopoulos, A. Complexing receptor pharmacology: modulation of family B G protein-coupled receptor function by RAMPs. Annals of the New York Academy of Sciences, 2006, 1070, 90-104. 

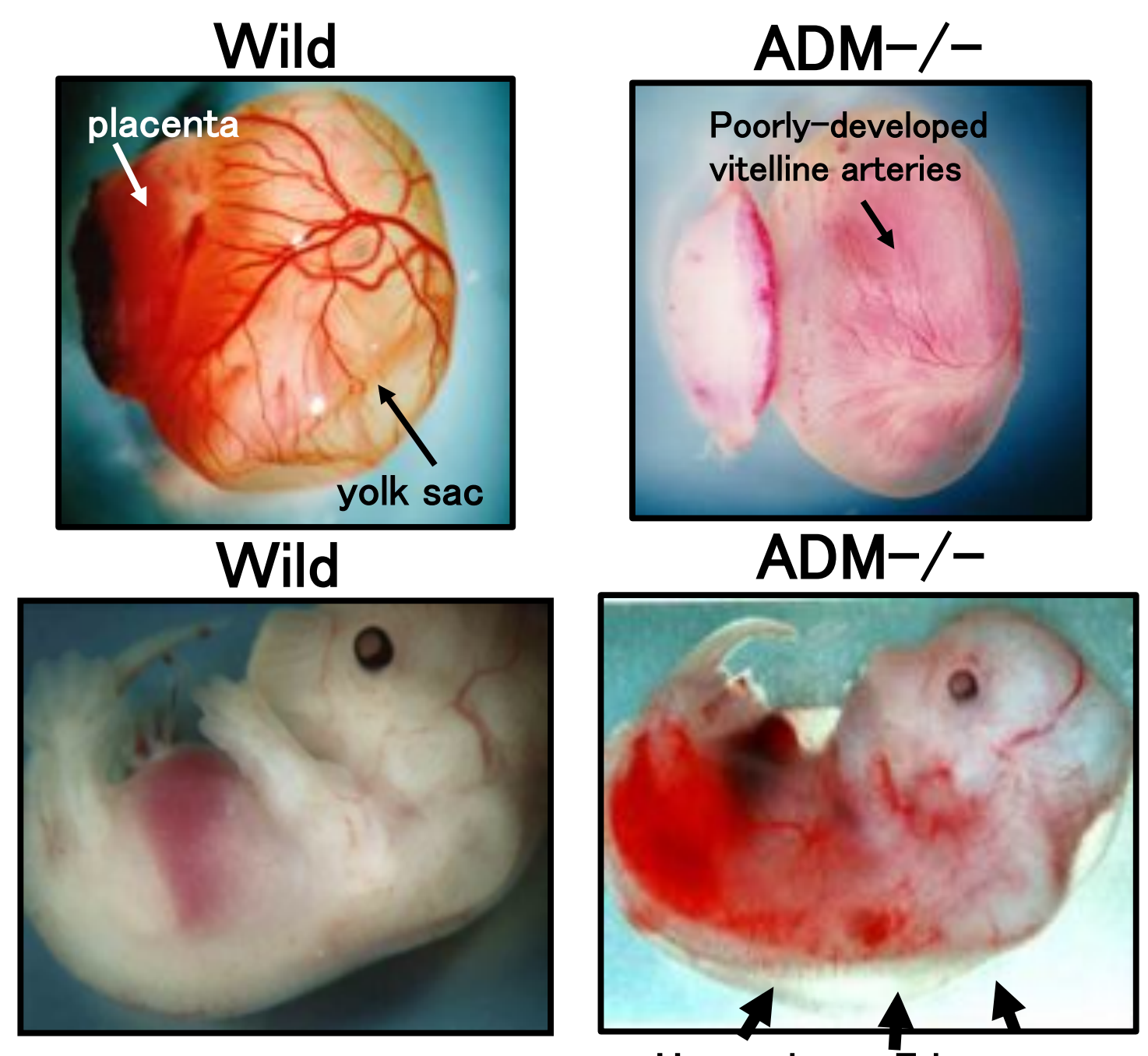

Hemorrhage, Edema

Figure 1 

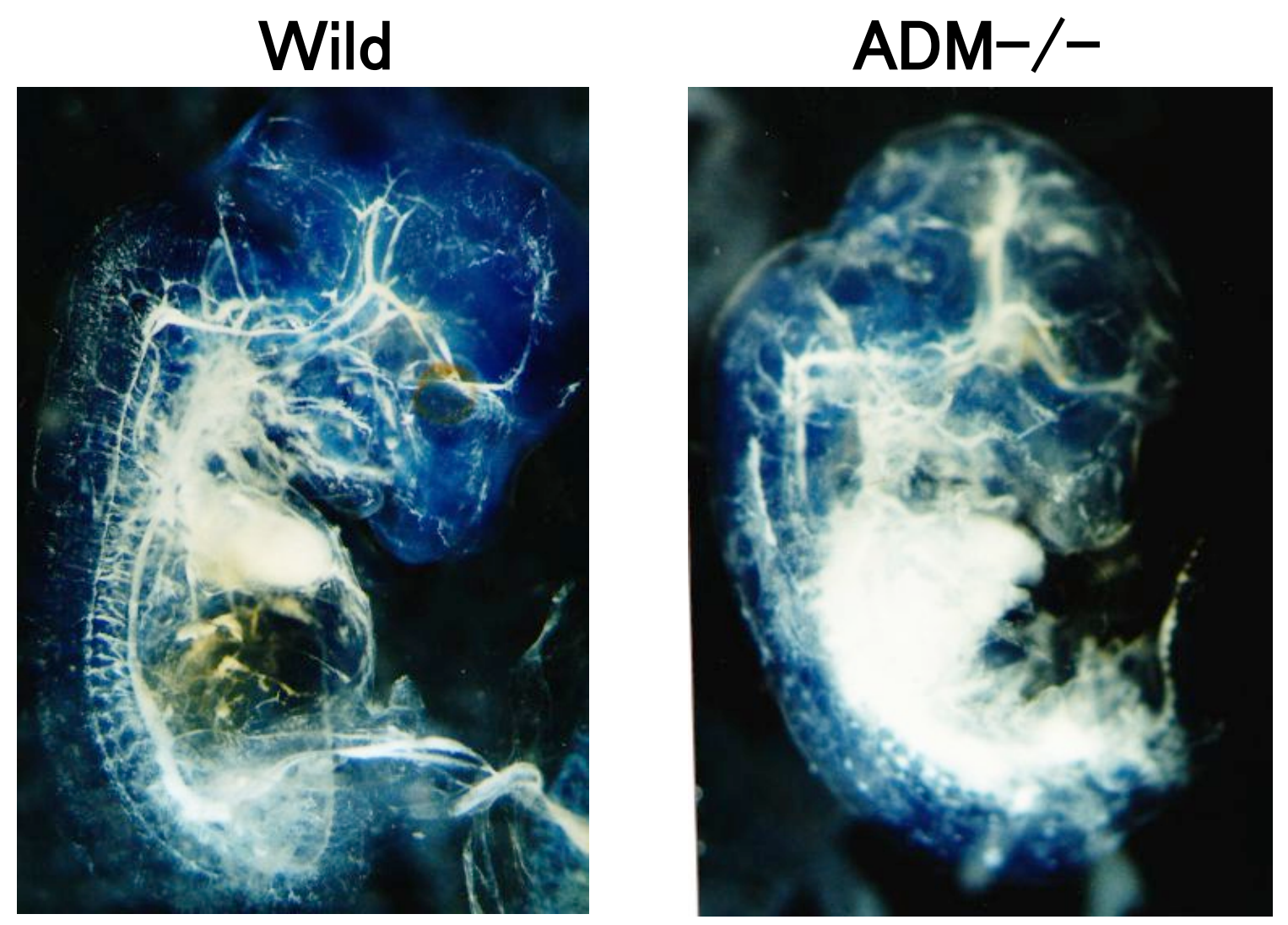

Figure 2 


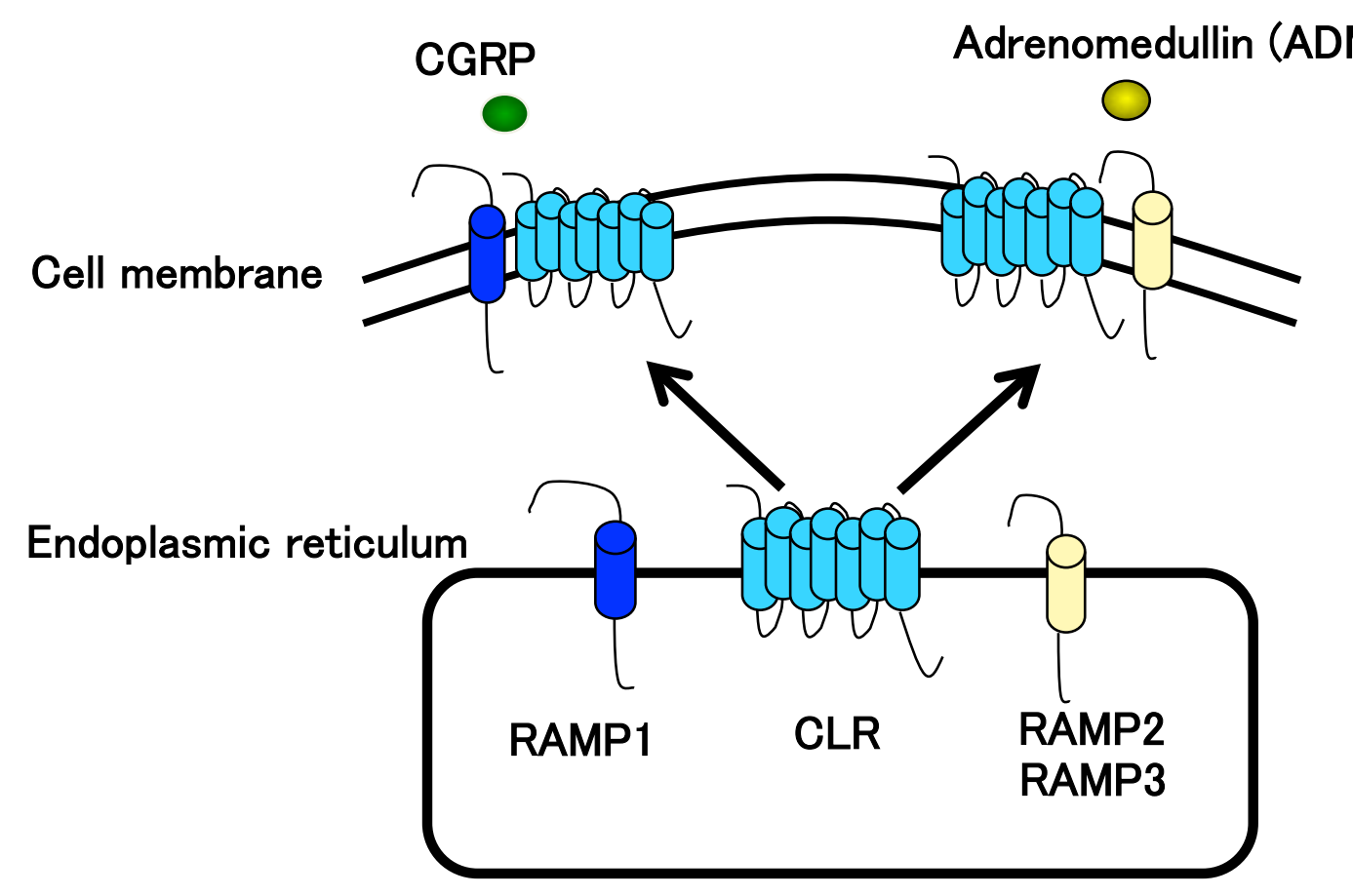

Figure 3 


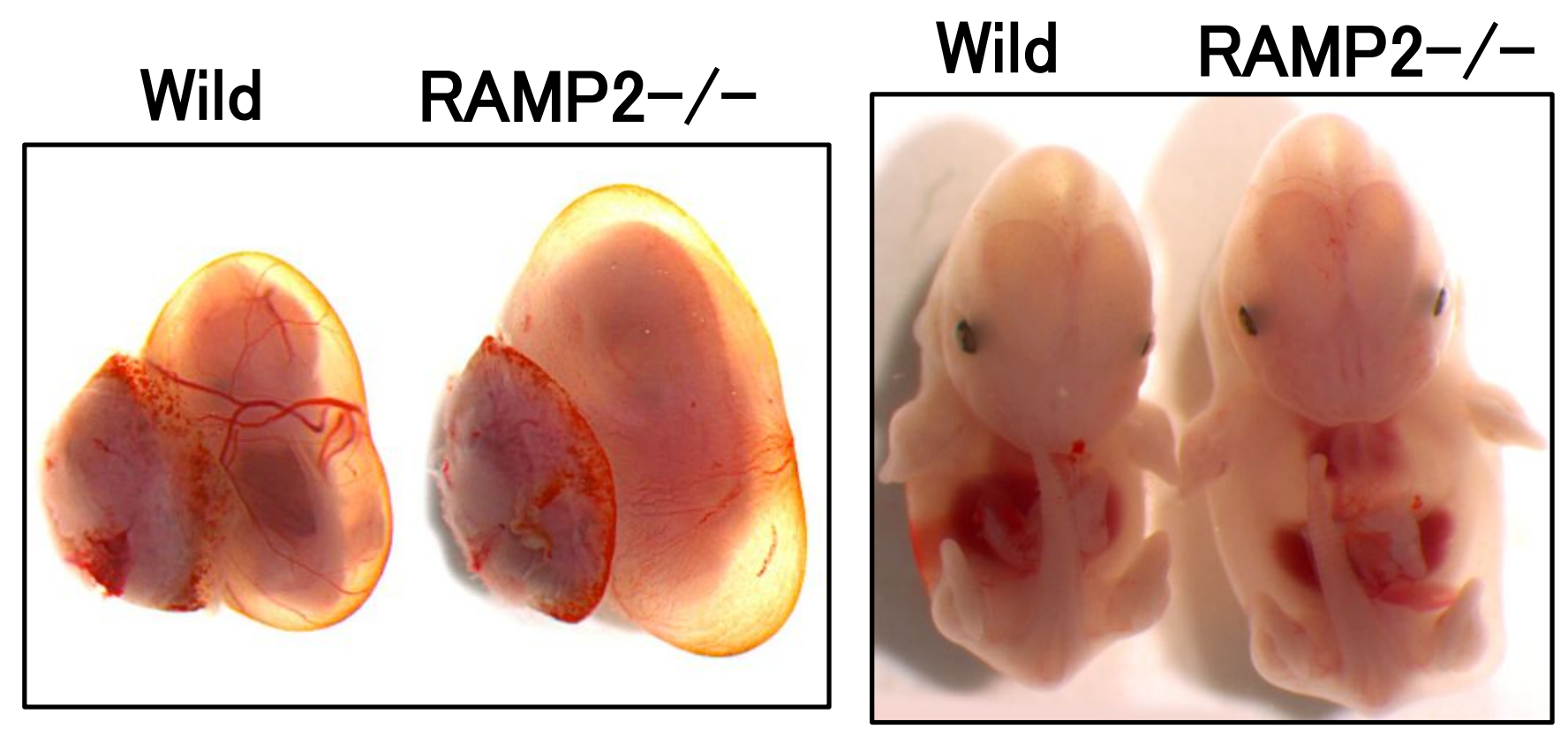

Figure 4 


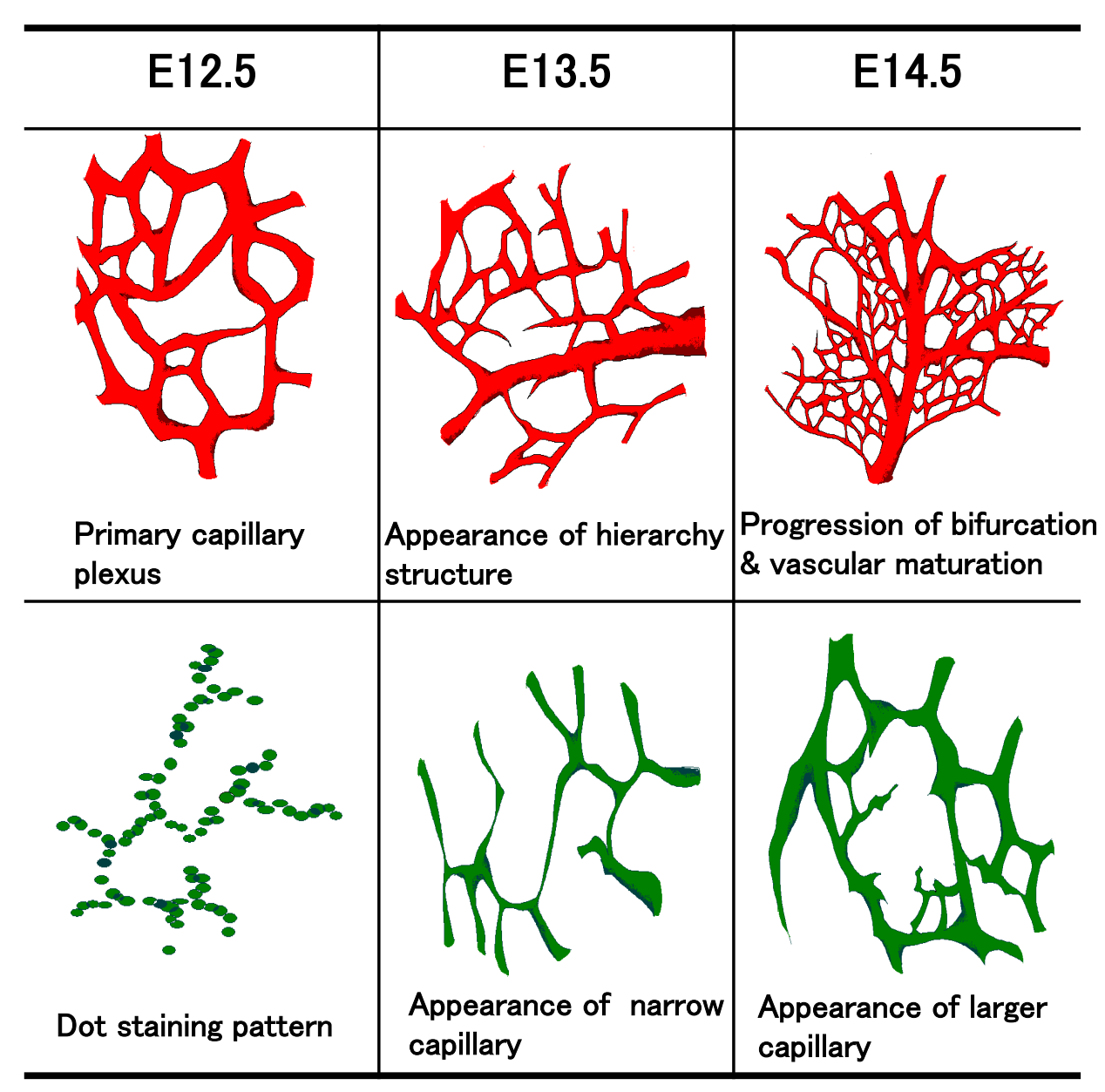

Figure 5 


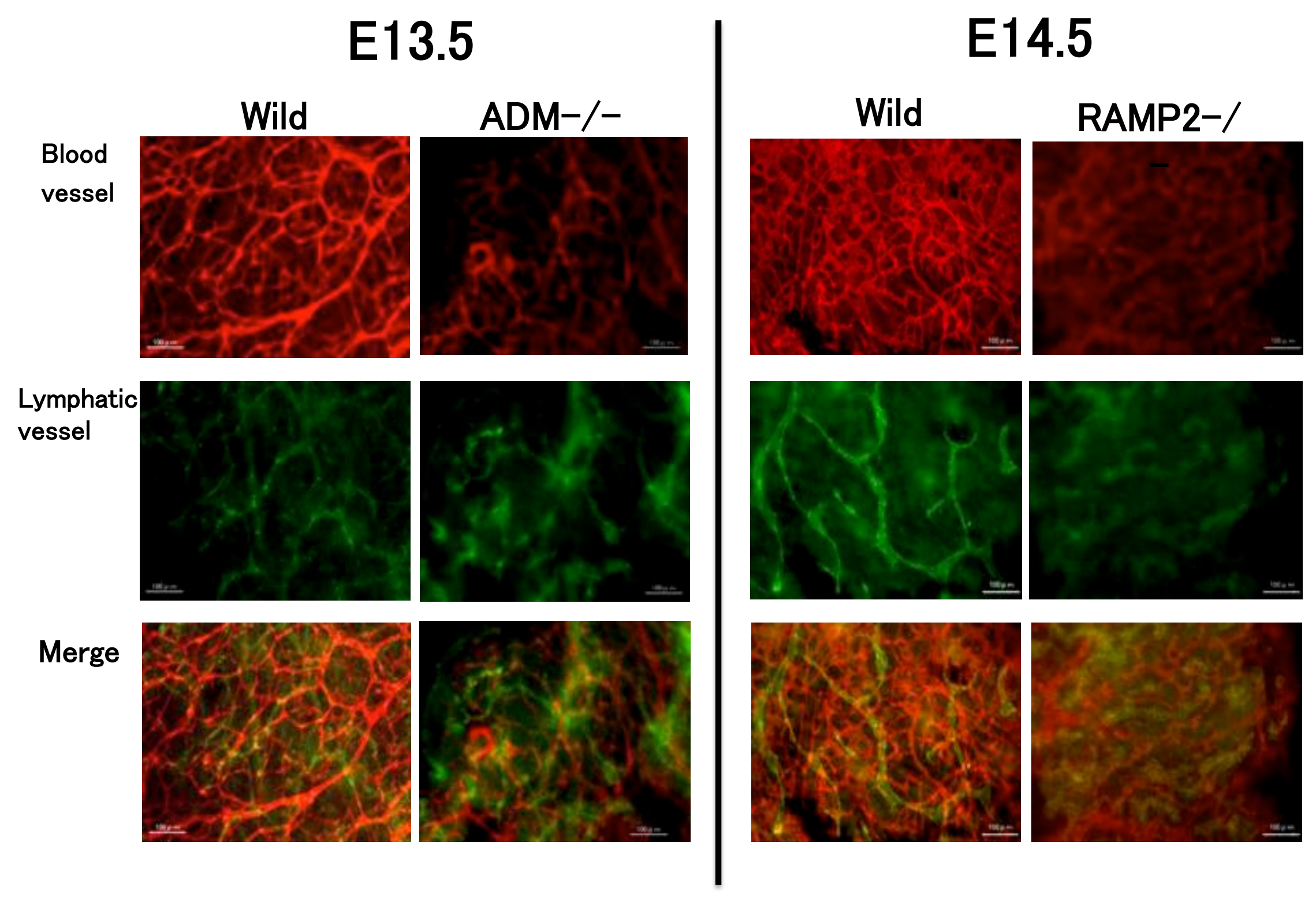

Figure 6 


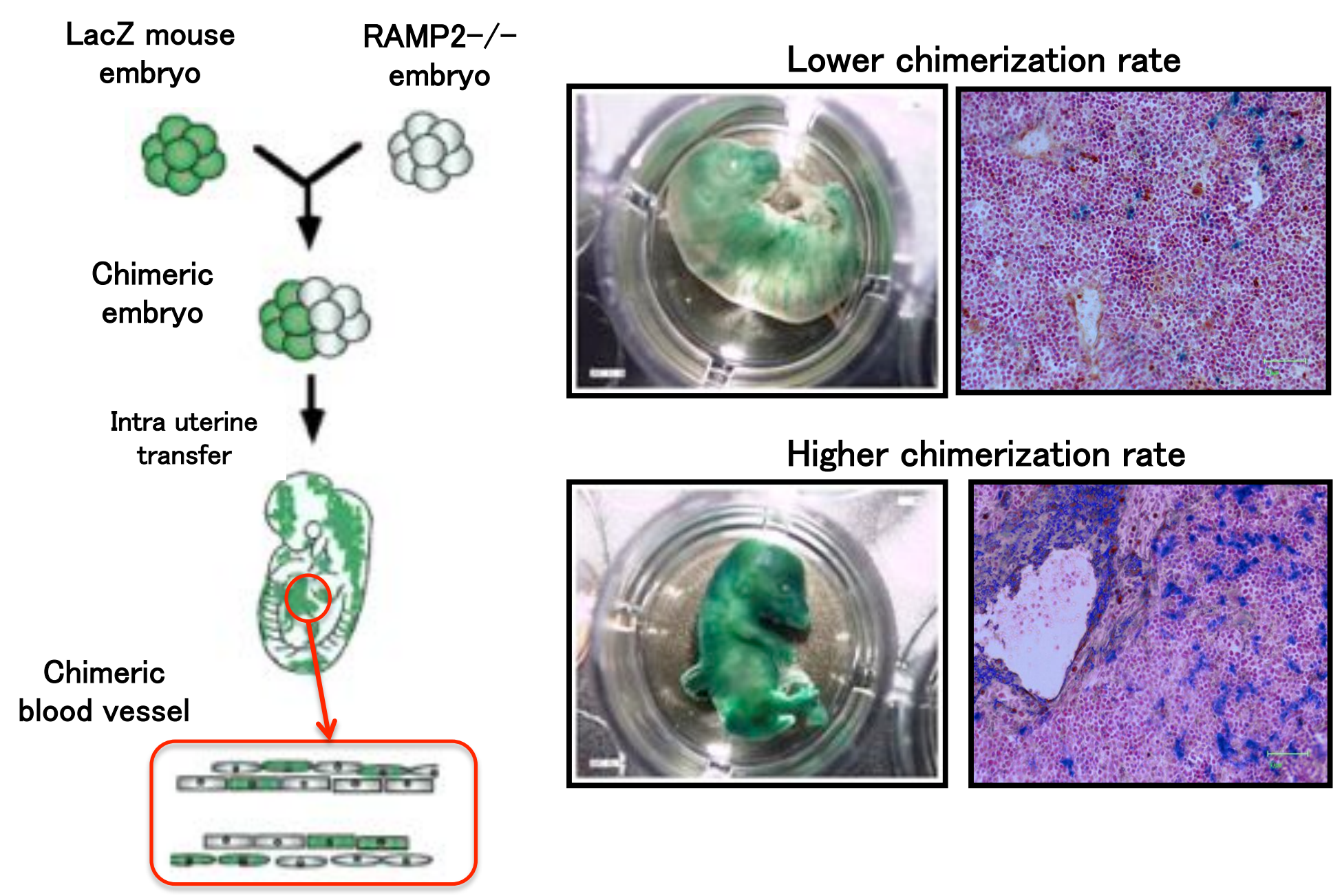

Figure 7 

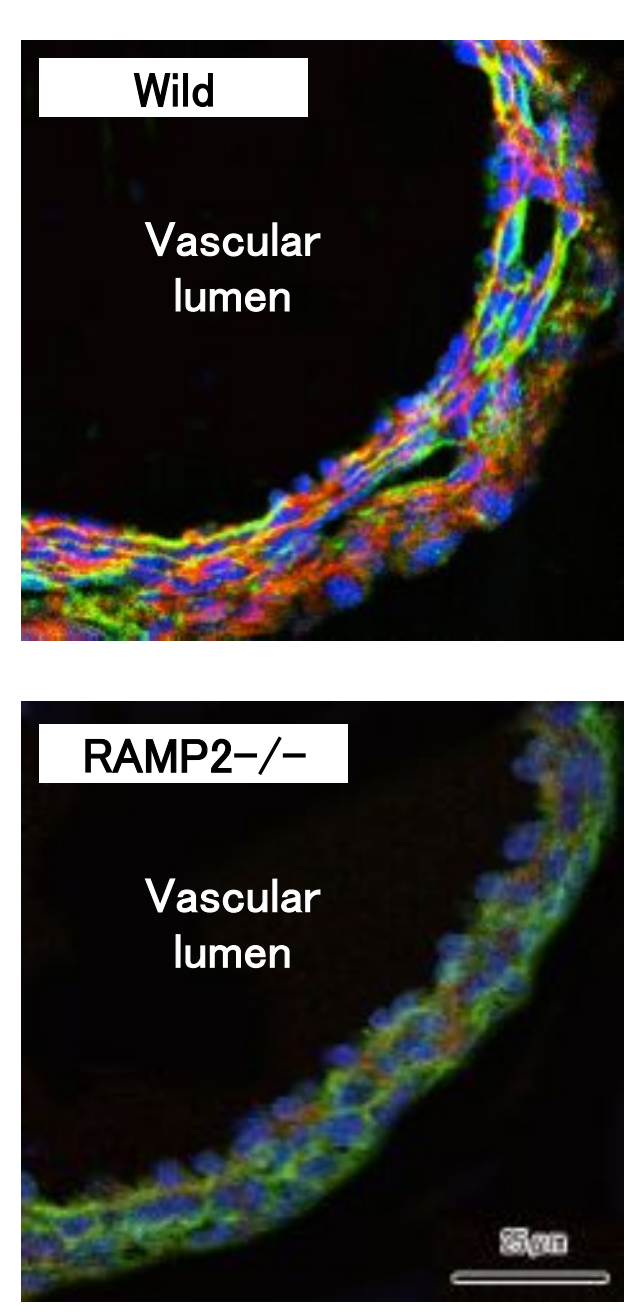

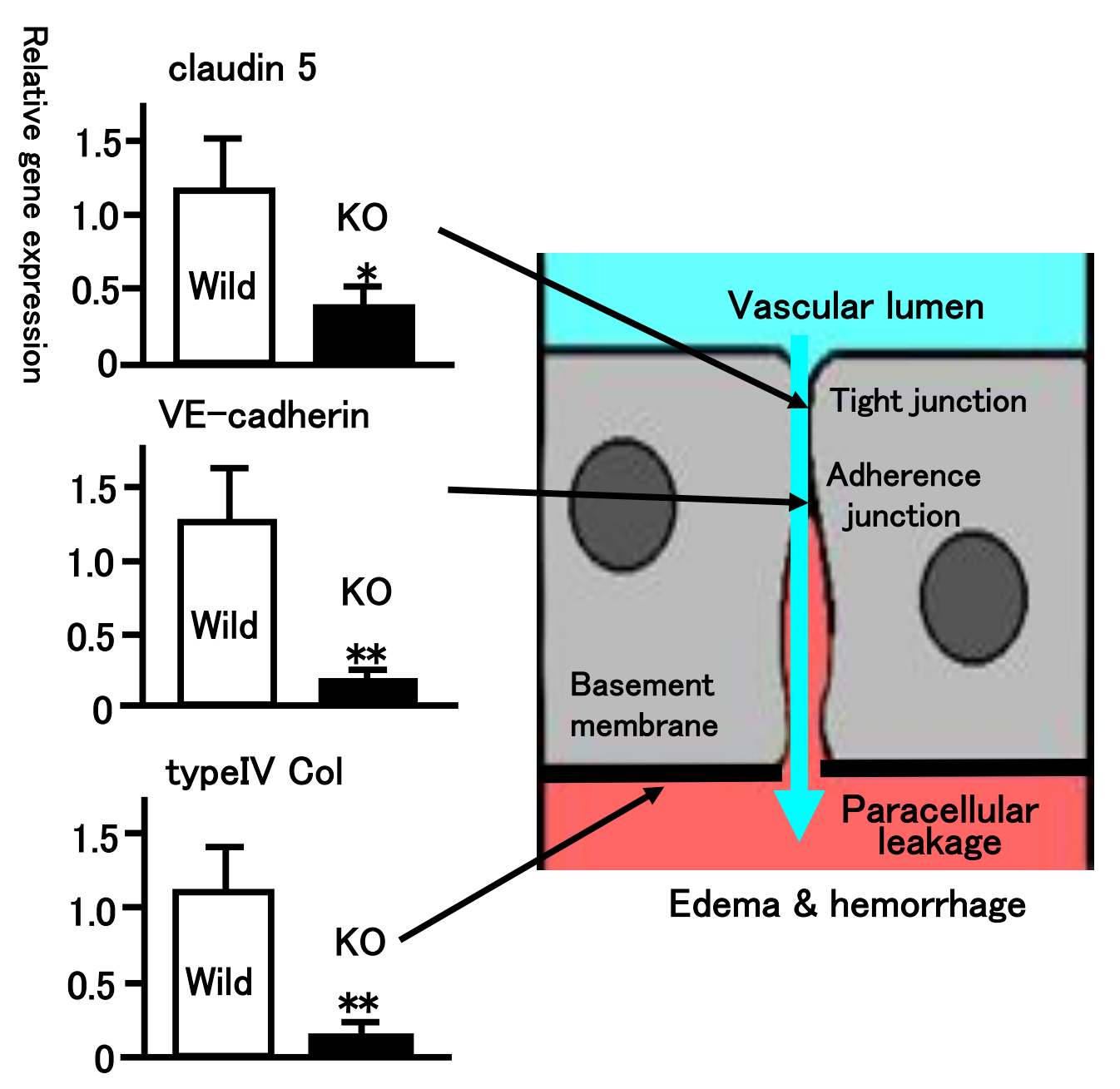

Figure 8 


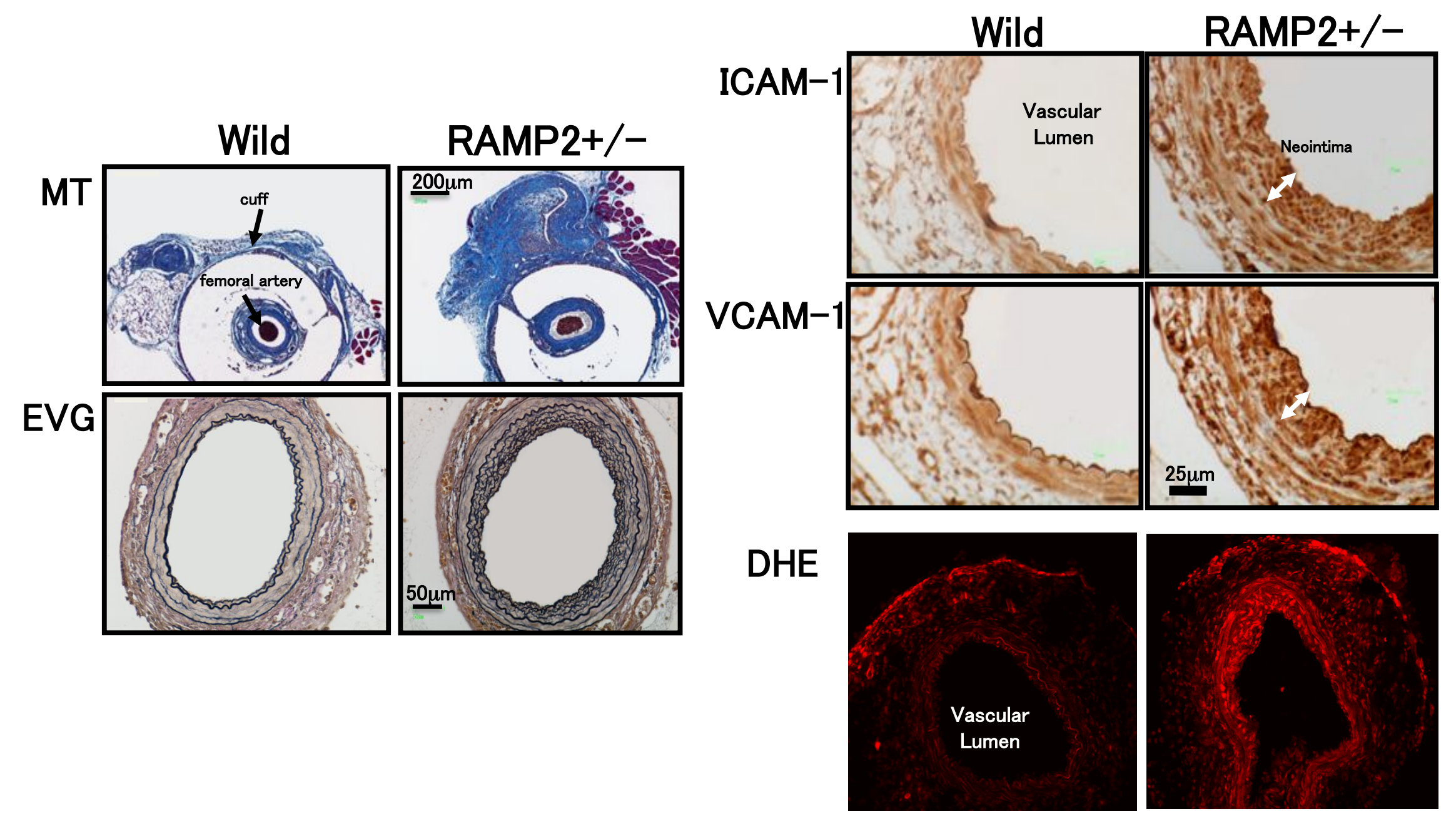

Figure 9 


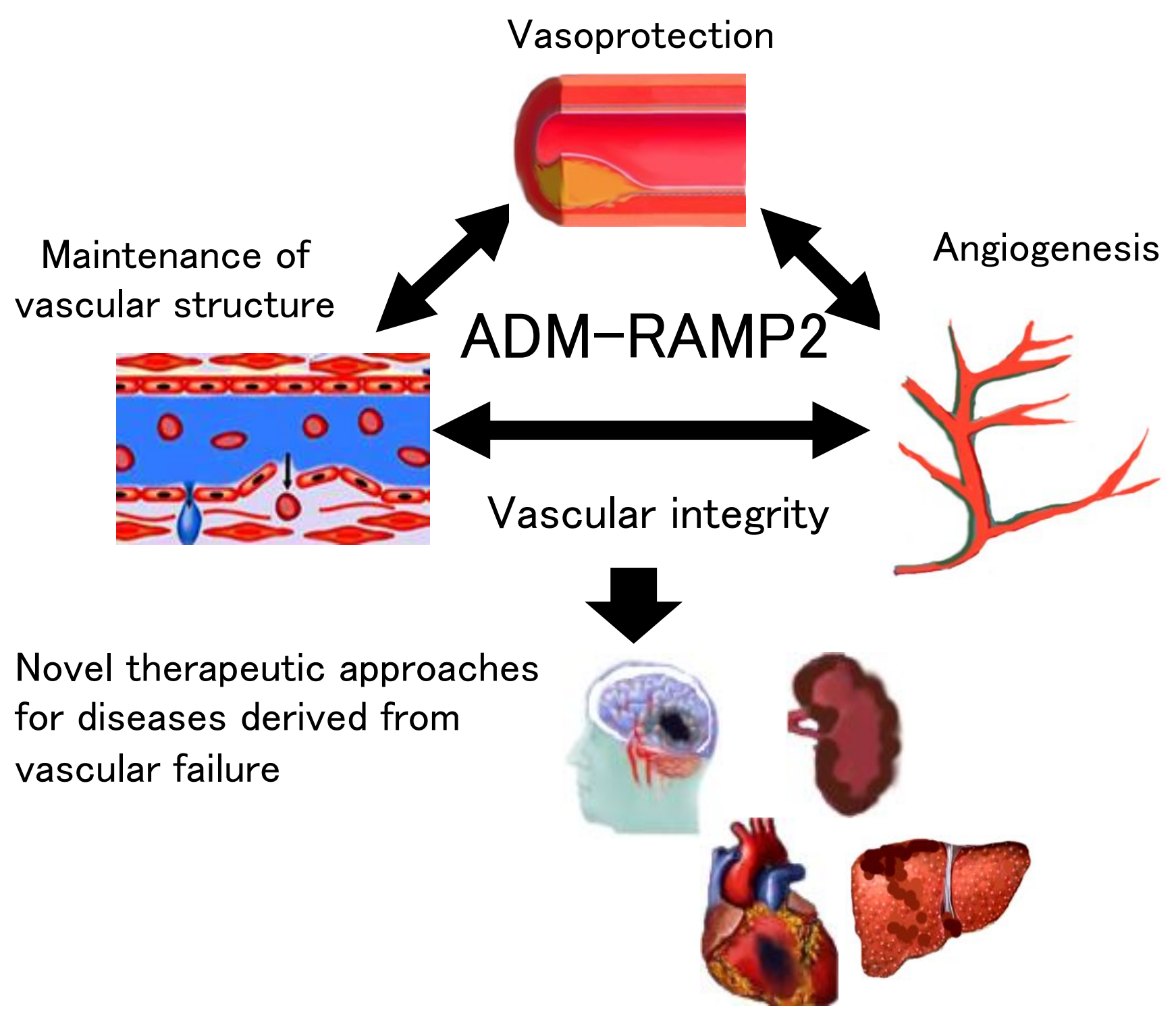

Figure 10 